\title{
Biomimicry for ecologically sustainable design in architecture: a proposed methodological study
}

\author{
D. A. Elmeligy \\ Department of Architecture Engineering, Tanta University, Egypt
}

\begin{abstract}
Biomimicry is a new way of viewing and valuing nature based not only on what can be extracted from the natural world, but also on what can be learned from it. Therefore, architects, designers and engineers have returned to their natural and biological roots to investigate and seek out solutions in design and performancebased problems within architecture. So architects are interested in biomimicry not only to find new ways of building, but also to find new sources of inspiration for aesthetic expression. In many cases, the results are buildings that are highly efficient, more durable and require less energy or fewer materials by using their language with nature to perform the adapted design concept. Well-known ecodesign was an attempt to preserve the resources (i.e. renewable or non-renewable resources) and to find ecological solutions by emulating nature's forms, processes and ecosystems to solve problems in architecture. Consequently, biomimicry is often described as a tool to increase the sustainability of human designed products, materials and the built environment.

So this research is focused on biomimicry as a potential approach that helps integrate ecological sustainability to design by understanding the natural processes to reach a proposed methodological study which contributes in clarifying the three-dimensional relationship between biomimicry, ecological design solution and sustainability which is most appropriate for architecture.

Keywords: biomimicry, ecological solutions, sustainable architecture, inspiration from nature.
\end{abstract}

\section{Introduction}

The differences between the technical realm and the natural realm cause the need for analogical thinking to allow for biomimetic design [2]. So this research will 
highlight biomimicry which inspires designs, and it involves finding positive solutions to design problems in architecture by emulating the natural world through clarifying the various levels and dimensions of biomimicry according to its approaches of design. Then, deep analytical study of these diverse approaches will be prepared to clarify different outcomes in terms of overall ecologically sustainable design. At the end of the study, in an attempt to propose a methodological study of the three-dimensional relationship between biomimicry, ecological design solutions and sustainability which is based on evaluating biomimicry in the case studies through their effectiveness in achieving ecologically sustainable design-focused goals. Furthermore, it will deduce a framework for understanding the application of biomimicry which redefines the different levels of it and also attempts to clarify the potential of biomimicry as a tool to increase ecologically sustainable solutions in architectural design.

\section{The scope and limitation of the research}

The scope and limitations that are used to define this research focus on studying and understanding how each of biomimicry and ecologically sustainable solutions work and how they are all interconnected in architecture. The subject areas that the research draws upon and the limitations of the research are illustrated in figure 1.

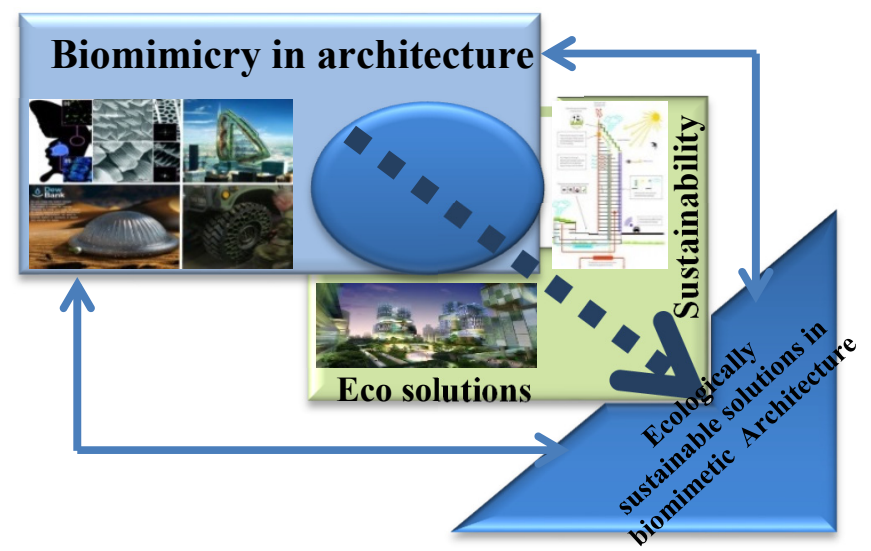

Figure 1: The scope and limitation of the research.

\section{Literature review}

The natural world is innovative and has been a source of inspiration for human beings, especially architects and designers, throughout the history of the world, starting in the $15^{\text {th }}$ century when Leonardo DaVinci took this type of mimicry from the birds and created drawings to depict a flying machine [27]. Then the need for analysing process of biomimicry is multiple because it is applied in almost every scientific and social field of work and research [4]. Therefore, the comparison between historical and contemporary biomimicry can be presented 
as the following to give information about the first outcrop, definitions and the main classification of biomimicry since its inception until now.

\subsection{A brief history of the term "biomimicry"}

\subsubsection{The first outcrop}

The portmanteau term "biomimicry" originates from the work of the multidisciplinary scientist Otto Schmitt (1913-1998) [4]. "Bio" comes from the Greek "bios" meaning life, and "mimicry" is from "mimesis" meaning imitation [7].

\subsubsection{Definition}

In 1974, the term "bio-mimetics" appeared in Webster's Dictionary [19], and was defined as: "the study of the formation, structure, or function of biologically produced substances, materials (as enzymes or silk), biological mechanisms and processes (as protein synthesis or photosynthesis) especially for the purpose of synthesis similar products by artificial mechanisms which mimic natural ones".

\subsubsection{Design approaches}

Biomimicry described in three parts [3]; using "nature's models" as inspiration for design that seek to solve human problems; using ecological standards to judge the effectiveness of innovations; and using biomimicry as a way to redefine how humans relate to nature [4].

\subsection{Contemporary biomimicry}

\subsubsection{The first outcrop}

As Hesselberg [28] explained, the percentage of papers with the term biomimetic published each year is increasing. This is confirmed by Gebeshiber et al. [29] who added that most publishing activity in the area of biomimicry comes from the research disciplines of bioengineering, chemical engineering and engineering physics. Then, there was a rapid increase in memberships of biomimetic related research networks. All of these increases help (human capacity) to understand and mimic nature in more meaningful ways and has been crucial to the emergence of biomimicry as a research area [23].

\subsubsection{Definition}

Nowadays, biomimicry is also defined as "mimicking the functional basis of biological forms, processes and systems to produce sustainable solutions" [1, 10]. So biomimicry is the suggested guiding principle to be a paradigm shift of creative and problem-based learning necessary for education toward sustainability $[24,25]$.

\subsubsection{Design approaches}

There are three main motivations behind investigating biomimicry. Biomimicry can be seen as a source of innovation in the creation of new materials and technologies; there is a rise in interest in the potential of biomimicry as a way to create more sustainable materials, products, built environments, and engineering 
solutions; and the third motivation for exploring biomimicry comes from a group of researchers who examine whether design based on an understanding of the living world could contribute to increase human psychological wellbeing, due to its inherent relationship with the concept of biophillia [12-14], where biophilic means the tendency to focus on life, and life-like processes [15, 20]. Therefore, design of biophilic seeks to incorporate an understanding of the processes of human psychological connection with the perceivable living world.

\section{Methodology}

In order to achieve the aims of this research, the methodology of it has relied on qualitative method through collecting data about the historical background of biomimicry and the theoretical basis of different levels and design approaches of biomimicry, analysing and interpreting data by observing how to use eco solutions as a tool to achieve sustainability in architecture. As well as using the correlational analysis to determine the strength of the relationship between biomimicry, ecological design solution and sustainability which is most applicable for architecture by using supporting evidence through an analytical approach of two case studies to clarify more the three-dimensional relationship between biomimicry, ecological design solutions and sustainability.

\section{Applying biomimicry in architecture}

Starting from the Biomimicry Institute, which has referred to this design approach and clarified it through the "challenge to the biology design spiral" (as shown in figure 2) $[5,8]$.

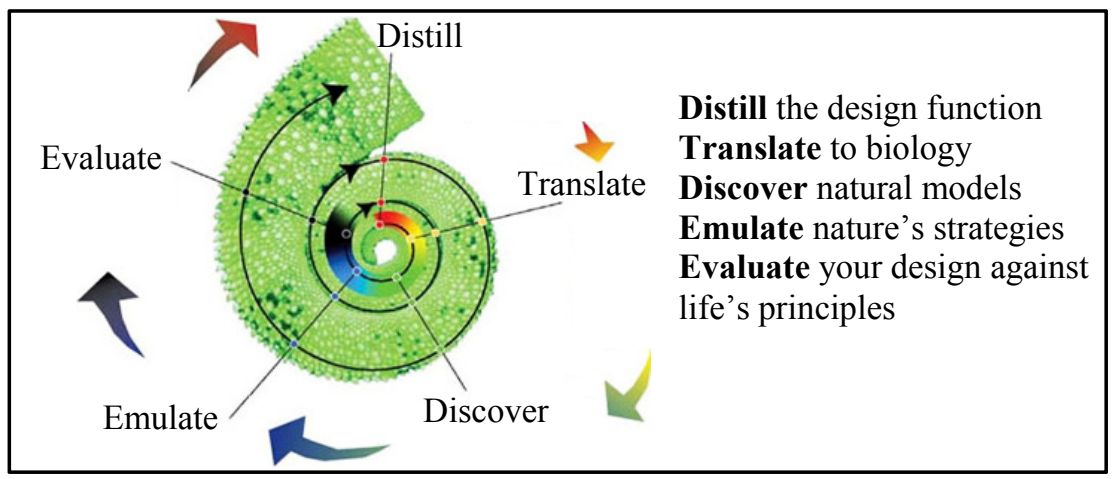

Figure 2: The challenge to the biology design spiral.

Furthermore, the design approaches of biomimicry typically fall into two main categories [9, 17, 18]: the direct approach, where a designer directly mimics strategies of an organism, a behavioural pattern or a system in nature with the aid of an analogical translation system. In addition, as it has two basic variations; where different schools of thought follow different steps. Some approaches understand design problems in two ways: from the perspective of 
design investigating biology and biology investigating design [22]. This includes defining a human need or design problem by understanding and conceptual is in processes and structures that other organisms or ecosystems use to resolve similar issues, while with the indirect approach, a designer abstracts ideas and concepts as principles from nature's designs (of natural system functioning). Otherwise, biomimetic as a design approach can also be conceptualized as a problem-driven approach and a solution-driven approach. Whilst, in the problem-driven approach, the designer begins with a problem that seeks to develop a solution, the solution-driven approach involves the designer taking a reverse-engineering approach in solving a design problem [21]. Therefore, through this research will be assembling the various design approaches of biomimicry with different levels and dimensions to become the first stone in the foundation which contribute to conclude the three-dimensional relationship between biomimicry, ecological design solution and sustainability (see figure 3 ).

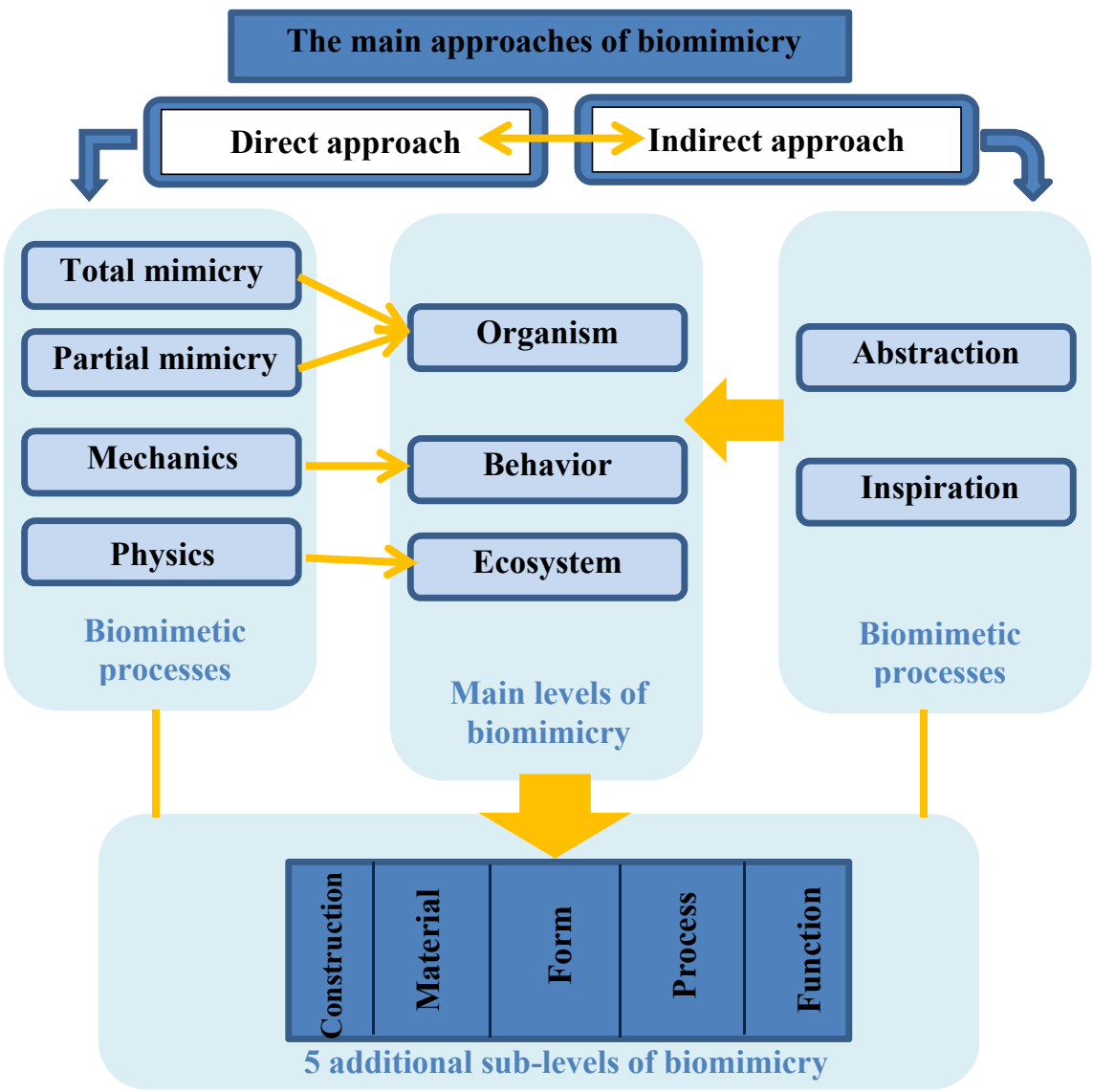

Figure 3: The various design approaches of biomimicry with different levels and dimensions. 


\section{Ecologically sustainable design in architecture}

Ecological and sustainable design focuses on the theory and practice of architectural and environmental design that makes maximum use of the same renewable flows of energy and material cycling processes by which all other living systems on earth are sustained. As it is well known that there are three principles of sustainability in architecture which can provide a broad awareness of the environmental impact (as shown in figure 4): Economy of resources is concerned with the reduction, reuse, and recycling of the natural resources that are input to a building, Life cycle design provides a methodology for analysing the building process and its impact on the environment, and Human design focuses on the interactions between human and the natural world [6].

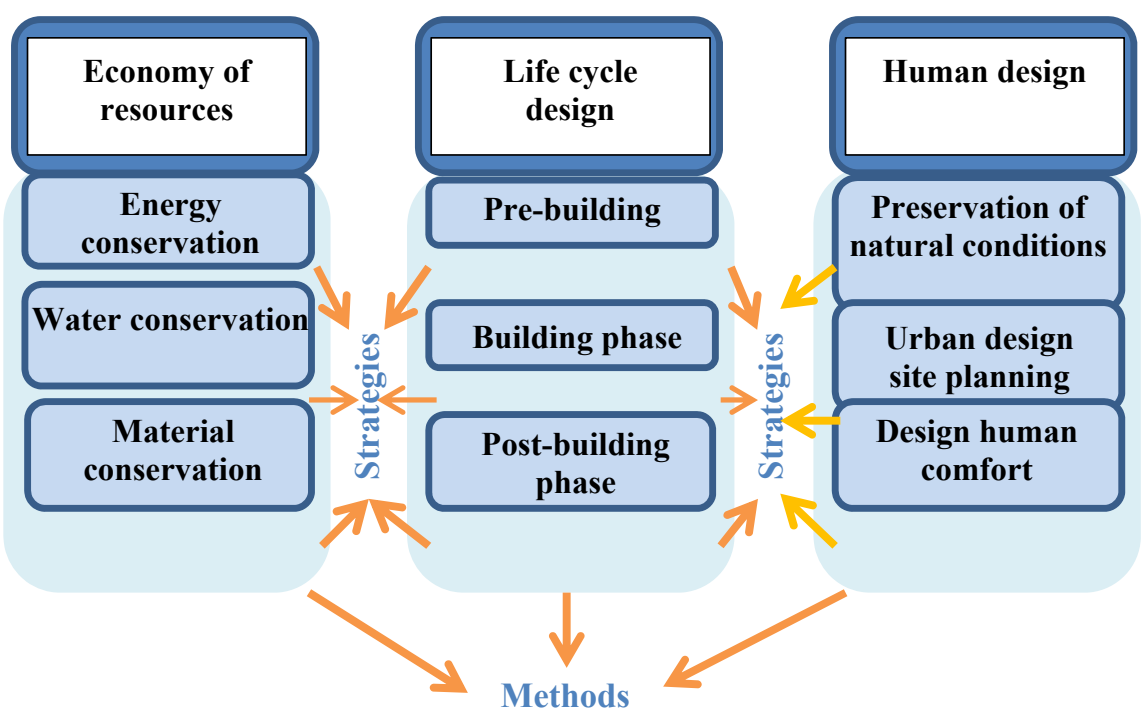

Figure 4: The different principles of sustainability in architecture.

A pertinent example is designing a bioclimatic house. In order to achieve sustainability by using the key elements bioclimatic design as one of the ecosolutions [11] (some of these key elements are represented in figure 5). 


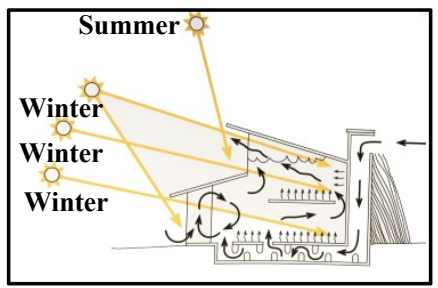

Bioclimatic design of buildings

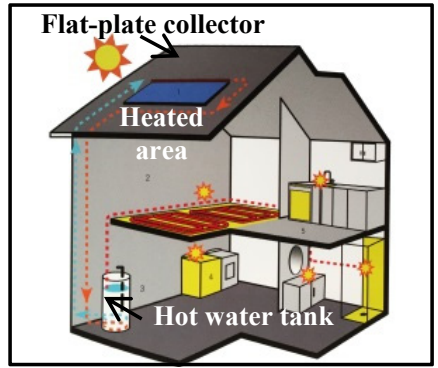

Thermal solar installation

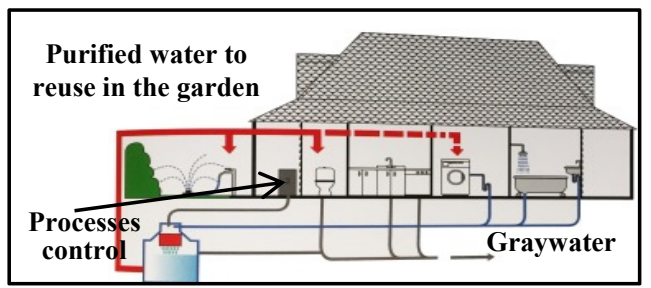

Wastewater purification system

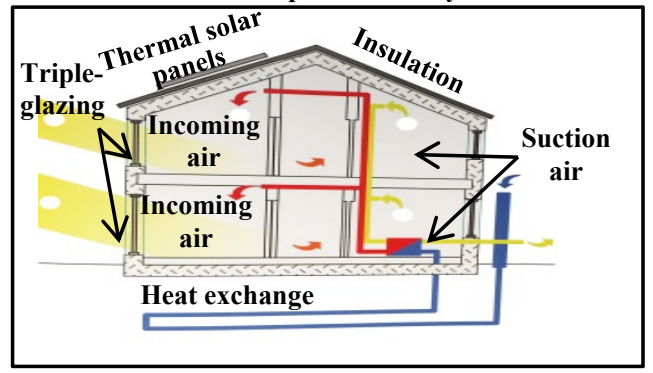

Ventilation system with heat recovery

Figure 5: Some of the key elements of bioclimatic design (Serrats [11]).

\section{Case studies of analysis based on the proposed methodology study}

From the foregoing it is clear that biomimicry is often described as a tool to increase the sustainability of human designed products, materials and the built environment [2]. As supposed biomimicry methods applied in order to implement sustainability in architecture where eco solutions are considered as a means to achieve this result more effectively. Therefore analysing the following case studies will further clarify more the three-dimensional relationship between biomimicry, ecological design solutions and sustainability.

\subsection{The first case study "Dragspelhuset"}

It is a private house where it considers an extension of an original cabin dating from the late $1800 \mathrm{~s}$, which is located on the shore of the lake Övre Gla in the nature reserve Glaskogen in Arjang, Sweden [15] (see figure 6).

\subsubsection{The main idea}

Maximize the possibilities where the designers created an extension that is capable of evolving through the ability of the building to adjust itself to its environment depending on the weather or the number of occupants.

\subsubsection{Biomimetic design approaches}

During the winter, the building is a cocoon with protection against the cold in the form of a double skin which unfurls in the summer like a butterfly for extra shelter during rainy days. The organic shape of the house of red cedar wood 


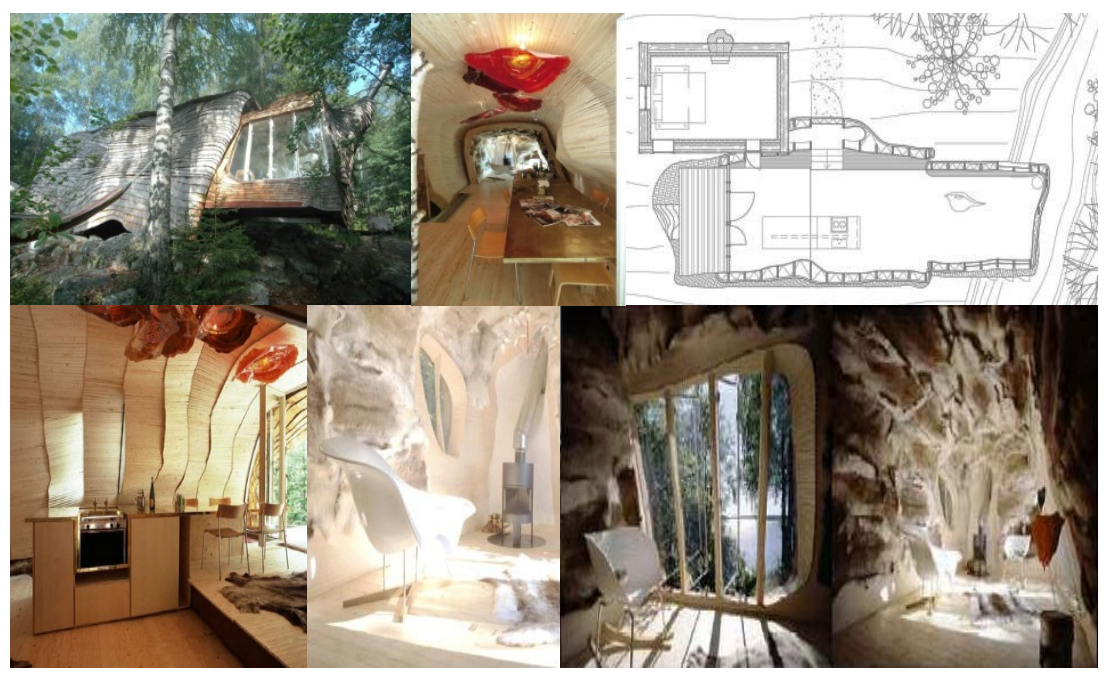

Figure 6: "Dragspelhuset": private house in Arjang, Sweden.

naturally blends into the forest setting. Following the tradition of the Sami tribe, reindeer hides are used in the interior as insulation [15].

\subsubsection{Ecological aspects}

Solar energy, running water directly from the stream, three wood stoves, including one for the bathtub; rainwater reuse composting outhouse and no maintenance due to untreated cedar wood.

\subsubsection{Degree of sealing}

$3 \%$ certificate/standard; the house is an almost $\mathrm{CO}_{2}$ free design zero energy building.

\subsection{The second case study: "BioVallo"}

The project was developed in Vallo di Diano, south of Salerno, Italy. This project is composed of a single masterplan that encompasses 13 subordinate projects for reuse and re-naturalization of 70 abandoned quarries in the Vallo di Diano Unesco site. Commissioned by the mountain community, BioVallo is a permanent exhibition at the Certosa di Padula [15] (see figure 7).

\subsubsection{The main idea}

The network of programs for the quarries is complex with many different complementary ideas and uses in order to build a new "green economy" for a neglected, beautiful area, where the innovation pavilion is the BioVallo infopoint, displaying all technologies used for the re-naturalization of the site.

\subsubsection{Biomimetic design approaches}

The whole development of the whole "bio-agriculture, bio-hub and bio-factory" is based on biotechnology, which is the key to success for a competitive society 
in the next 100 years. Especially the BioHub which contains the physical support for the development and the know-how around the main concept: materials based on algae, biofuels, use of organic photosynthesis, etc., are all aspects which will be developed. Also the pavilion skin consists of translucent bioplastic filled with water and algae [15].

\subsubsection{Ecological aspects}

Solar energy, wind, micro-Aeolian, micro hydro-electrical, micro- photovoltaic energy, solar heat and rainwater reuse.

\subsubsection{Certificate/standard}

It consumes $\mathrm{CO}_{2}$ for the manufacturing of products which are generated within the area itself; zero energy building.

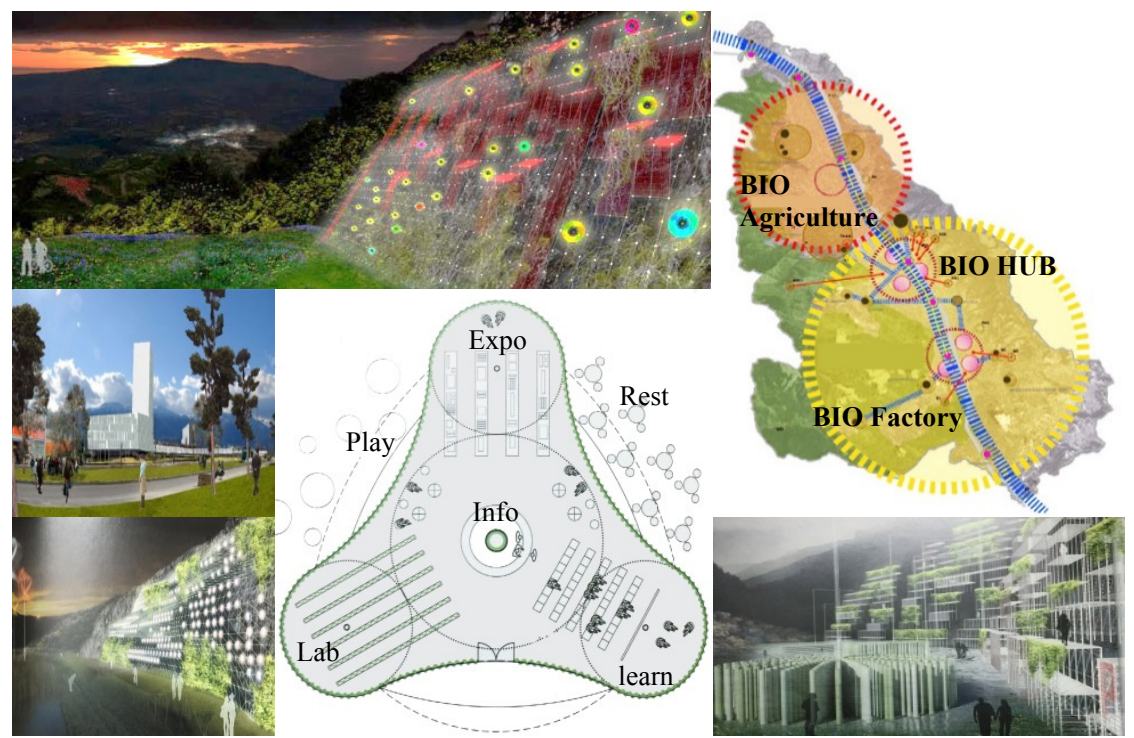

Figure 7: "Bio Vallo" in Vallo di Diano, south of Salerno, Italy.

\subsection{The third case study: "hydrogenase airship"}

This is a huge scientific project proposed by renowned Belgian architecture firm, Vincent Callebaut Architecture for the Chinese government. It designed for the South China Sea near Shanghai $[16,26]$. The project itself consists of an algae farm, bio-hydrogen airship, emergency housings, scientific laboratories and how to solve the increasing cost of freight in the near future. For flights up to 2000 meters level, the biohydrogen airship could carry up to 200 tons of freight at a maximum speed of $175 \mathrm{kph}$; double the speed of a ship and $7 \mathrm{x}$ slower than an airplane (see figure 8). 


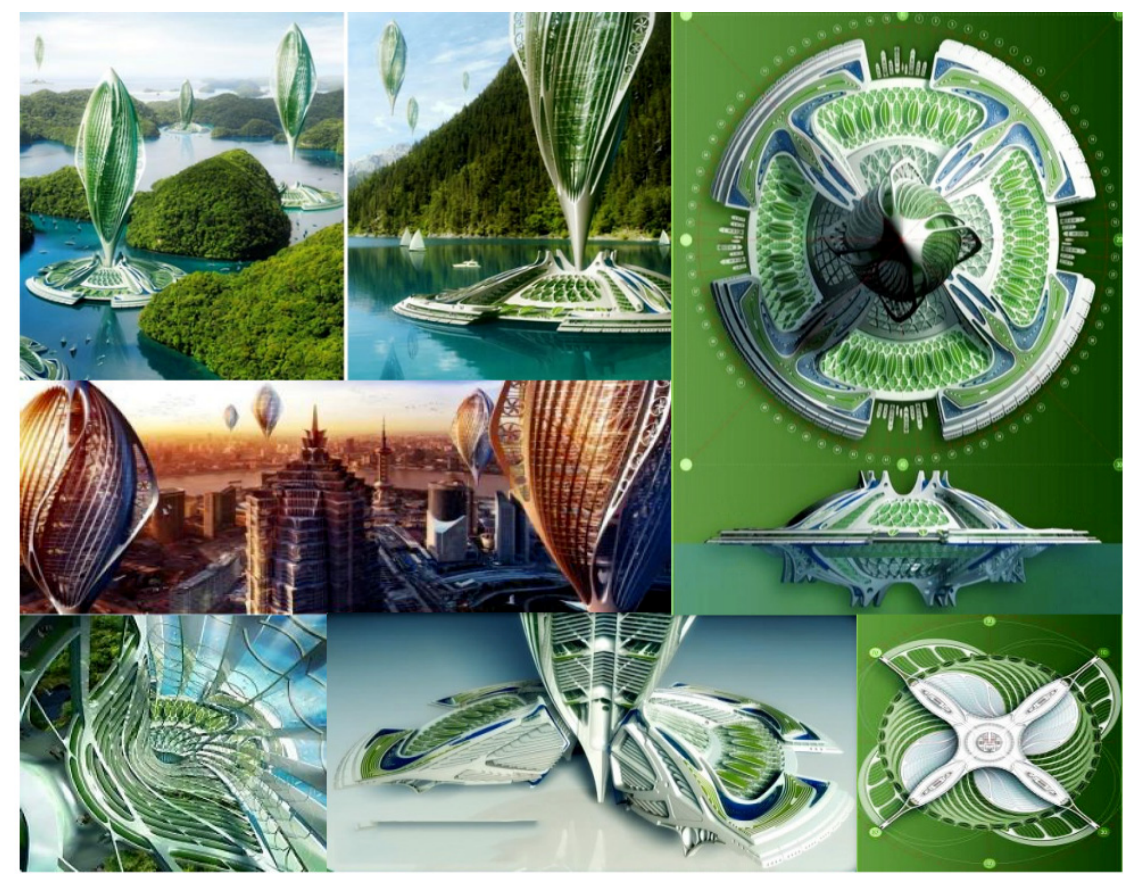

Figure 8: The scientific project proposed "Hydrogenase airship", for the South China Sea near Shanghai.

\subsubsection{The main idea}

Callebaut's hydrogenase airships are completely self-sufficient and contain specialized breeds of seaweed that soak up sunlight and $\mathrm{CO}_{2}$ to generate hydrogen.

\subsubsection{Biomimetic design approaches}

The hydrogenase airship is one of the first projects involving bio-mimicry, which draws its inspiration from the beautiful shapes of nature and the qualities of its materials and generation processes, where algae producing airborne cities are $100 \%$ emission-free and are capable of generating hydrogen gas without consuming land needed for crops or forests [16].

\subsubsection{Ecological aspects}

The habitable vertical airship has the potential for relying solely on green energy to function, with zero carbon emissions, thus offering a new way to travel that is clean and ethical.

\section{Conclusion}

So through analysing the previous projects as shown in table 1, it can be deduced that the ecological aspects are considered the result of using biomimicry methods 
Table 1: The three-dimensional relationship in the previous case studies.

\begin{tabular}{|c|c|c|c|c|c|c|}
\hline 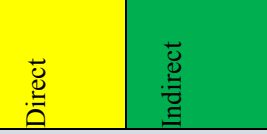 & \multicolumn{2}{|c|}{$\begin{array}{l}\text { Case study } 1 . \\
\text { Dragspelhuset }\end{array}$} & \multicolumn{2}{|c|}{$\begin{array}{l}\text { Case study } 2 . \\
\text { Bio Vallo }\end{array}$} & \multicolumn{2}{|c|}{$\begin{array}{l}\text { Case study } 3 . \\
\text { Hydrogenase } \\
\text { airship }\end{array}$} \\
\hline Organism & \multirow[t]{2}{*}{ - } & \multirow{18}{*}{$\begin{array}{l}\text { - The building } \\
\text { is a cocoon in } \\
\text { the form of a } \\
\text { double skin } \\
\text { - Like a } \\
\text { butterfly for } \\
\text { extra shelter } \\
\text { during rainy } \\
\text { days } \\
\text { - The organic } \\
\text { shape of the } \\
\text { house of red } \\
\text { cedar wood } \\
\text { - Reindeer } \\
\text { hides are used } \\
\text { in the interior } \\
\text { as insulation }\end{array}$} & \multirow{12}{*}{\multicolumn{2}{|c|}{$\begin{array}{l}\text { - It is based on } \\
\text { biotechnology } \\
\text { especially in } \\
\text { Bio-Hub } \\
\text { "materials } \\
\text { based on algae, } \\
\text { biofuels, use of } \\
\text { organic } \\
\text { photosynthesis, } \\
\text { etc..." } \\
\text { - The pavilion } \\
\text { skin consists of } \\
\text { translucent } \\
\text { bioplastic filled } \\
\text { with water and } \\
\text { algae }\end{array}$}} & \multirow{10}{*}{\multicolumn{2}{|c|}{$\begin{array}{l}\text { - The algae- } \\
\text { producing } \\
\text { airborne cities } \\
\text { are } 100 \% \\
\text { emission-free } \\
\text { and are capable } \\
\text { of generating } \\
\text { hydrogen gas } \\
\text { without } \\
\text { consuming } \\
\text { land needed for } \\
\text { crops or } \\
\text { forests. }\end{array}$}} \\
\hline construction & & & & & & \\
\hline material & $\bullet$ & & & & & \\
\hline form & - & & & & & \\
\hline process & & & & & & \\
\hline function & & & & & & \\
\hline Behavior & - & & & & & \\
\hline construction & & & & & & \\
\hline material & $\bullet$ & & & & & \\
\hline form & & & & & & \\
\hline process & - & & & & - & \\
\hline function & & & & & - & \\
\hline Ecosystem & & & $\bullet$ & & - & \\
\hline construction & & & & & & \\
\hline material & & & & & & \\
\hline form & & & & & & \\
\hline process & & & $\bullet$ & & $\bullet$ & \\
\hline function & & & & & - & \\
\hline $\begin{array}{l}\text { Ecological aspects in } \\
\text { case studies }\end{array}$ & & $\begin{array}{l}\text { Ir energy- } \\
\text { water reuse- } \\
\text { naintenance }\end{array}$ & & $\begin{array}{l}\text { ar energy/heat- } \\
\text { d- rainwater } \\
\text { se - micro.... }\end{array}$ & & $\begin{array}{l}\text { n energy - zero } \\
\text { on emissions }\end{array}$ \\
\hline Economy of resources & ㅁ & & घ & & घ & \\
\hline Energy conservation & 口 & & - & & $\mathbf{\square}$ & \\
\hline Water conservation & 口 & & 匹 & & & \\
\hline Material conservation & - & & & & & \\
\hline Life cycle design & & & & & $\mathbf{\square}$ & \\
\hline Pre-building & & & & & & \\
\hline Building phase & & & & & घ & \\
\hline Post-building phase & & & & & & \\
\hline Human design & ㅁ & & 口 & & $\mathbf{\square}$ & \\
\hline Natural conditions & घ & & घ & & & \\
\hline Site planning & & & ㅁ & & & \\
\hline Human comfort & - & & 口 & & - & \\
\hline
\end{tabular}

to perform the adapted design concept which in turn they applied in order to achieve sustainability.

A result of all of the foregoing is to determine and clarify deeply the threedimensional relationship between biomimicry, ecological design solutions and 
sustainability which is based on evaluating biomimicry case studies through their effectiveness in achieving ecologically sustainable design-focused goals. It can be deduced that the present and future ambitions for the whole world drive towards promoting ecological solutions in architecture under increasing pressure to preserve the natural resources and use them very cautiously which in turn is the main focus of sustainability, on the other hand Biomimicry may just be the way to achieve this. Creating a sustainable built environment is not done by integrating just solar panels on every building, but humans need to be more intune with nature and look at nature for inspiration, while biomimicry use has generally been considered to be a new discipline to solve human problems, so it can be used as an integrative architectural design component in order to achieve ecological sustainable design, and create complete unity between the building, the users, and the environment.

\section{References}

[1] Anous I. H., "Biomimicry - innovative approach in interior design for increased sustainability", International Association of Scientific Innovation \& Research (IASIR), USA, pp. 18-27, 2015.

[2] Braganca L., Pinheiro M., Jalali S., Mateus R., Amoeda R. \& Guedes M.C., "Sustainable construction; materials \& practices", IOS Press, Netherlands, 2007.

[3] Benyus J., "Biomimicry-innovation inspired by nature", New York, Harper Collins Publishers, 1997.

[4] Benyus, J. M., "Biomimicry: innovation inspired by nature" (3rd ed.), NY: Williams and Morrow \& Co., 2002.

[5] Kevin R Murray, "Classification of biological phenomena to aid in search and retrieval for biomimicry". Master Thesis, Clemson University, USA, p. 4, May 2013.

[6] Kim J.-J., "Sustainable architecture module: introduction to sustainable design", National pollution prevention centre for higher education, college of architecture \& urban planning, Michigan University, USA, 1998.

[7] Maglic M. J., "Biomimicry: using nature as a model for design" Master Thesis, University of Massachusetts, Amherst, p. 4, May 2012.

[8] McGregor, S. "Transdisciplinary and Biomimicry", Faculty of education Mount Saint Vincent University, Canada, Vol. 4, pp. 57-65, December, 2013.

[9] Panchuk N., "An exploration into biomimicry and its application in digital \& parametric", (architectural design), Master thesis, Waterloo, Ontario, Canada, 2006.

[10] Pawlyn, M., "Biomimicry in architecture", London: RIBA publishing, p. 4, 2011.

[11] Serrats M., "Eco-solution, sustainable approaches for a bioclimatic home", Frechmann Kolon Gmbh (FKG), China, 2012. 
[12] Stephen R. Kellert, Judith H. Heerwagen, Martin L. Mador, "Biophilic Design", The theory, science, and practice of bringing buildings to life, John Wiley \& Sons, 2005.

[13] Stephen R. Kellert, Elizabeth F. Calabrese, "The practice of Biophilic Design", articles available online http://www.bullfrogfilms.com/guides/ biodguide.pdf 2008.

[14] Stephen Davies, "The artful species - aesthetics, art, and evolution", Oxford University Press, First edition published 2012.

[15] Uffelen C.V., "Ecological Architecture", BRAUN publishing AG, Swiss, 2010.

[16] Vidiella A. S., "Atlas of eco architecture", Frechmann Kolon Gmbh (FKG), China, 2010.

[17] Vincent, J., "Deployable structures in nature", centre for biomimetic, University of Reading, UK, 1st edition, 2001.

[18] Vincent, J., Bogatyreva, O.A, Bogatyrev, N.R., Bowyer, A. \& Pahl, A., "Biomimitics - its practice and theory", Journal of the Royal Society Interface, 3, pp. 9471-482, 2006.

[19] Vincent, "Deployable structures in engineering", S. Pellegrino, University of Cambridge, Cambridge, UK, 2002.

[20] Wilson, "Biophilia, The human bond with other species", Cambridge, Harvard University Press, p. 1, 1984.

[21] Wilson J.O., "A systematic approach to bio-inspired conceptual design", Doctor thesis, Georgia Institute of Technology, p. 7, 2008.

[22] Zari, M.P., "Biomimetic approaches to architectural design for increased sustainability", School of Architecture, Victoria University, Wellington, New Zealand, No. 033, 2007.

[23] Zari M.P., "Ecosystem services analysis for the design of regenerative urban built environments", A thesis for the degree of doctor of philosophy, Victoria University of Wellington, New Zealand, 2012.

[24] Zejnilovic E., Husukic E., "Biomimicry in Architecture", International Journal of Engineering Research and Development, Vol. 11, pp. 75-84, July 2014.

[25] http://www.biomimicry.info/reviewoftheliterature

[26] http://thecoolgadgets.com/bio-hydrogen-airshiphydrogenase-selfsufficient-architectural-plans-for-2030/\#ixzz3zqHnDe3x

[27] Science channel, http://curiosity.discovery.com/question/the-history-of biomimicry (2011)

[28] https://www.researchgate.net/publication/6585927_Biomimetics_and_the case_of_the_remarkable_ragworms

[29] https://www.researchgate.net/profile/Herbert/stachelberger2/publication/ 228907802 tribology in biology biomimetic studies across dimensions and across fields/links 